\title{
Finite Element Analysis of Spherical Ultrasonic Motor using Wire Stator
}

\author{
Fulin Wang, Uichi Nishizawa, and Shigeki Toyama
}

\begin{abstract}
The authors are developing multi degree of freedom micro spherical ultrasonic motor using wire stator for endoscope. In the previous study, the authors investigated the driving characteristics by using a single spiral wire stator of 15 times model as experimental equipment. In this study, assuming the introduction of a vascular endoscope, the authors design a wire stator and perform a transient response analysis by the finite element method. It is aimed to investigate the influence of the attenuation of the traveling wave transmitted on the wire stator by changing the condition of the model by this analysis. In the future, the authors will measure the amplitude of the wire stator by experiment and verify the accuracy of the simulation.
\end{abstract}

Index Terms-Ultrasonic motor, spherical rotor, wire stator, finite element analysis.

\section{INTRODUCTION}

Cardiovascular disease caused by hardening of the arteries is a serious disease in the world. The diagnosis of this vascular disease is an important subject, and various methods are being studied. Particularly in recent years, vascular endoscopic techniques, which have made great progress such as enabling a visualization of the aorta, have attracted particular attention. Vascular endoscope can grasp the state of diseased parts in blood vessel macroscopically and is the only way that information can be obtained as a three-dimensional color image. However, since the diameter of the endoscope is very small, it is impossible to mount a general multi degree of freedom actuator. For this reason, the camera can not be directed in any direction, and it is difficult to photograph the lesion on the inner wall of the blood vessel at the center of the image.

As a solution to this problem, the authors are developing multi degree of freedom micro spherical ultrasonic motor using wire stator for endoscope. The imaginal diagram of micro spherical ultrasonic motor is shown in Fig. 1. In the previous study, the authors investigated the driving characteristics by using a single spiral wire stator of 15 times model as experimental equipment. In this study, assuming the introduction of a vascular endoscope, the authors design a wire stator and perform a transient response analysis by the finite element method. It is aimed to investigate the influence of the attenuation of the traveling wave transmitted on the wire stator by changing the condition of the model by this analysis.

Manuscript received February 20, 2018; revised April 12, 2018.

Fulin Wang, Uichi Nishizawa, Shigeki Toyama are with Tokyo University of Agriculture and Technology, Koganei, Tokyo, JAPAN (e-mail: zjwangfulin@163.com, n-uichi@cc.tuat.ac.jp, toyama@cc.tuat.ac.jp).

\section{The SPHERICAL UltRASONIC MOtor Using WiRE STATOR}

The schematic diagram of spherical ultrasonic motor is shown in Fig. 2. It is composed of a Langevin transducer, a wire stator, and a spherical rotor. In the previous study, polycarbonate is used for the spherical rotor and SUS304 is used for the wire stator as the material of the motor. This is because the propagation efficiency of ultrasonic vibration is considered to be good because the value of the specific acoustic impedance of stainless steel is large. The experimental equipment used in previous study is shown in Fig. 3. When ultrasonic vibration is applied to one end of the wire stator, a traveling wave is generated toward the other end, and the surface of the wire stator performs elliptical motion in the direction opposite to the traveling wave. The spherical rotor receives frictional force at the contact surface with the wire stator due to elliptical motion and rotates in the direction opposite to the traveling wave. By making one pair of wire stators, it is possible to drive one axis by sandwiching the spherical rotor, and by making two pairs to hold the spherical rotor from the four directions, it becomes two-axis drive. In the wire stator, there are two waveguides inside and outside of coil. The direction of the traveling wave can be changed by the connection method of the Langevin transducer, and the rotation direction of the rotor can be reversed. In addition, by simultaneously connecting both waveguides, it is possible to generate a standing wave that does not affect the driving. The main feature of the motor using the wire stator is that the number of parts is small, the structure is simple, it is suitable for miniaturization, and it does not affect the electric field and magnetic field.

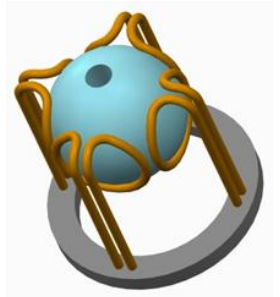

Fig. 1. Imaginal diagram of micro spherical ultrasonic motor.

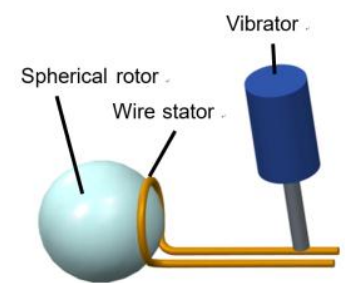

Fig. 2. Schematic diagram of micro spherical ultrasonic motor. 


\section{ANALYSIS MODEL OF LONG WAVEGUIDE WIRE STATOR}

\section{A. Analysis of long Waveguide Wire Stator}

The length of a vascular endoscopic catheter is about $2 \mathrm{~m}$, but the waveguide with the wire stator used in the previous study was $30 \mathrm{~mm}$. In this study, the authors assume the introduction of a vascular endoscope and design the waveguide with the wire stator extended to $2 \mathrm{~m}$ as shown in Fig. 4. The wire stator used in the experiment is 15 times model. The size of long waveguide with wire stator and the wire stator used for experiment in previous study is shown in TABLE I. In order to investigate the damping of vibration applied to the wire stator, a transient response analysis is performed by the finite element method. The model used for finite element analysis is shown in Fig. 5. A displacement input is made to the node at one end of the wire stator in the conditions as shown in TABLE II, and the displacement of the node of the coil part, which is the contact part with the spherical rotor, is outputted. For comparison, a finite element model of the wire stator used in the previous study as shown in Fig. 6 is also made. In this model transient response analysis is performed by inputting the displacement in the same condition as the $2 \mathrm{~m}$ waveguide. In this study, Femap with NX Nastran is used for finite element analysis.

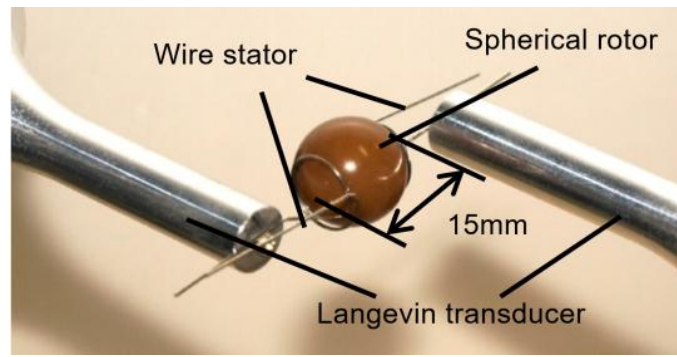

Fig. 3. Spherical ultrasonic motor using wire stator.

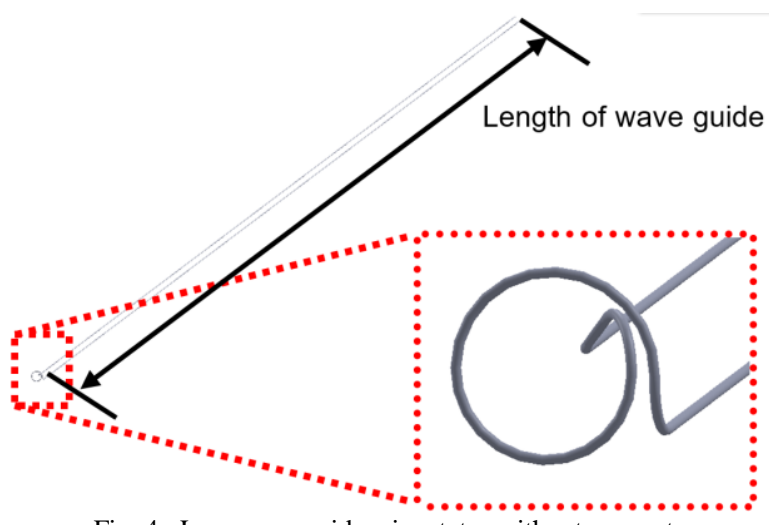

Fig. 4. Long waveguide wire stator without support.

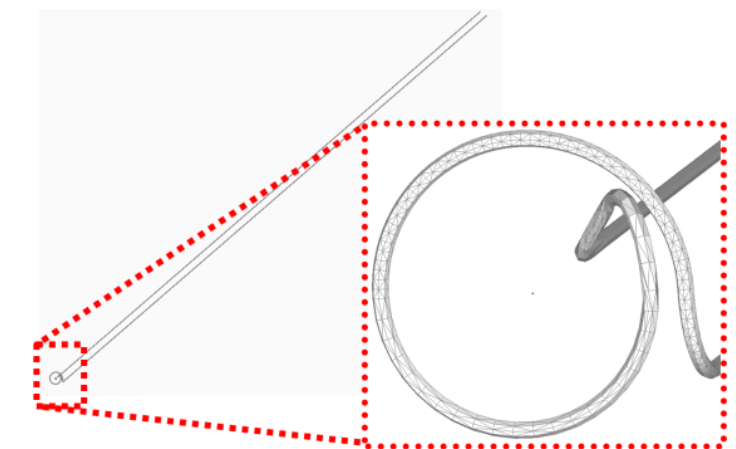

Fig. 5. Analysis model of long waveguide wire stator without support.

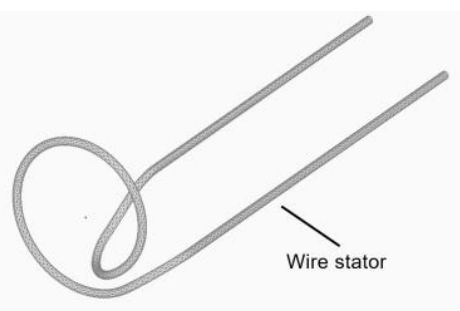

Fig. 6. Analysis model of experimental wire stator without support.

TABLE I: SIZE OF WIRE STATOR

\begin{tabular}{l|c|c}
\hline \hline & $\begin{array}{c}\text { Experimental wire } \\
\text { stator }\end{array}$ & $\begin{array}{c}\text { Long wave guide } \\
\text { wire stator }\end{array}$ \\
\hline Length of wave guide $(\mathrm{mm})$ & 30 & 2000 \\
\hline Outside diameter of coil $(\mathrm{mm})$ & \multicolumn{2}{|c}{10} \\
\hline Wire diameter $(\mathrm{mm})$ & \multicolumn{2}{|c}{0.5} \\
\hline \hline
\end{tabular}

\begin{tabular}{l|l}
\multicolumn{2}{c}{ TABLE II: SimULATION CONDITIONS } \\
\hline \hline Input waveform (-) & Sine pulse \\
\hline Frequency $(\mathrm{kHz})$ & 24.6 \\
\hline Amplitude $(\mathrm{m})$ & 0.01 \\
\hline Simulation time $(\mathrm{s})$ & 0.03 \\
\hline Sampling time $(\mathrm{s})$ & $5.0813 \times 10^{-6}$ \\
\hline \hline
\end{tabular}

\section{B. Analysis Result of long Waveguide Wire Stator}

The displacement from $0.0025 \mathrm{~s}$ to $0.003 \mathrm{~s}$ in the coil part of each stator obtained by analysis as shown in Fig. 7. It can be seen that the amplitude of the coil part of the long waveguide is clearly reduced as compared with short waveguide. The amplitude of the stator with the $2000 \mathrm{~mm}$ waveguide is $0.026 \mathrm{~mm}$ and the amplitude of the stator with the $30 \mathrm{~mm}$ waveguide is $0.081 \mathrm{~mm}$, which is decreased by $68.4 \%$. In the previous study, the driving characteristic is evaluated by changing the voltage applied to the Langevin resonator, which is the vibration source. At that time, the displacement due to the vibration of the tip of the Langevin resonator is measured with a laser displacement meter. As a result, it is known that in the range of $60 \mathrm{Vp}$-p or less, as the applied voltage increases, the amplitude of the displacement input made to the wire stator increases. The decrease in input displacement at each voltage difference is shown in Fig. 8. From this figure, it can be seen that the decreasing rate of the amplitude is $68.4 \%$, which is obtained by extending the waveguide by about 67 times, and it almost agrees with the decreasing rate by decreasing the applied voltage by $30 \mathrm{Vp}-\mathrm{p}$. From the above, it can be considered that the damping of vibration is affected by extending the waveguide and it can be reproduced by changing the input of the Langevin transducer without using the same size experimental equipment.

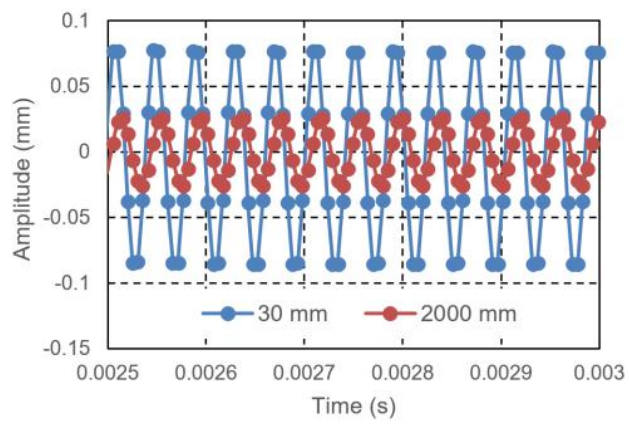

Fig. 7. Amplitude of coil part. 


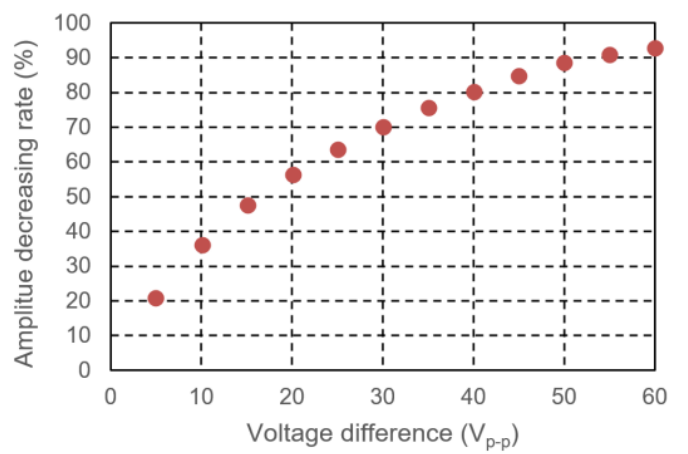

Fig. 8. Relations of voltage difference and amplitude decreasing rate.

\section{ANALYSIS MODEl OF SUPPORT WAVEGUIDE WIRE STATOR}

\section{A. Analysis of Support Waveguide Wire Stator}

As described in Section III. A, assuming the introduction of a vascular endoscope, the wire stator is $2 \mathrm{~m}$. Therefore, it is necessary to support the waveguide during operation. As shown in Fig. 9, a support structure is added to the model of the wire stator in this study, and a transient response analysis is performed by the finite element method. All the materials of the added structure are SUS304, which is the same as the material of the stator, and the line of the rod-like part is the same as the stator. The displacement input made in the model is added to this support structure in the conditions shown in Table II. In the input, the direction perpendicular to the support rod is defined as the $\mathrm{x}$ direction, and the parallel direction is defined as the y direction, and the displacement in the node of the coil part is outputted in these two directions.

\section{B. Analysis result of support waveguide wire stator}

The analysis results are from $0.0025 \mathrm{~s}$ to $0.003 \mathrm{~s}$ shown in Fig. 10 when the displacement input is made in the $\mathrm{x}$ direction, and the analysis results from $0.0025 \mathrm{~s}$ to $0.003 \mathrm{~s}$ shown in Fig. 11 when the displacement input is made in the y direction.

As shown in Fig. 8, the amplitude in the coil part of the stator having the support structure in the waveguide is 0.058 $\mathrm{mm}$, and the amplitude in the coil part of the stator having no support structure in the waveguide is $0.081 \mathrm{~mm}$. From this result, when the displacement input is made in the direction perpendicular to the support rod, the influence on the amplitude of the support appears as a decrease of $27.3 \%$. Further, as shown in Fig. 9, the amplitude in the coil part of the stator having the support structure in the waveguide is $0.091 \mathrm{~mm}$ and the amplitude in the coil part of the stator having no support structure in the waveguide is $0.27 \mathrm{~mm}$. From this result, when the displacement input is made in the direction parallel to the support rod, the influence on the amplitude of the support appears as a decrease of $66.8 \%$. Comparing these two results, the amplitude is decreased by $39.5 \%$ when displacement input is made in the y direction rather than in the $\mathrm{x}$ direction. The reason for this result is that excitation in the $y$ direction is difficult because the support structure is not easily bent due to the structure and the amplitude is suppressed by direct support. From the above, it can be confirmed that the vibration transmitted to the coil part varies depending on the direction of the displacement input made to the tip with the same support structure. In addition, more attenuating appears as the traveling wave close to parallel to the support structure.

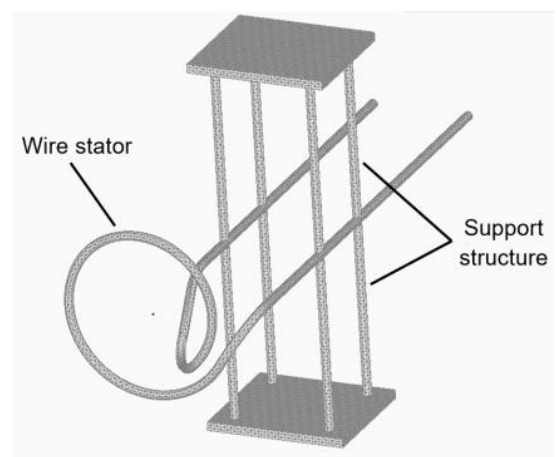

Fig. 9. Analysis model of wire stator with support.

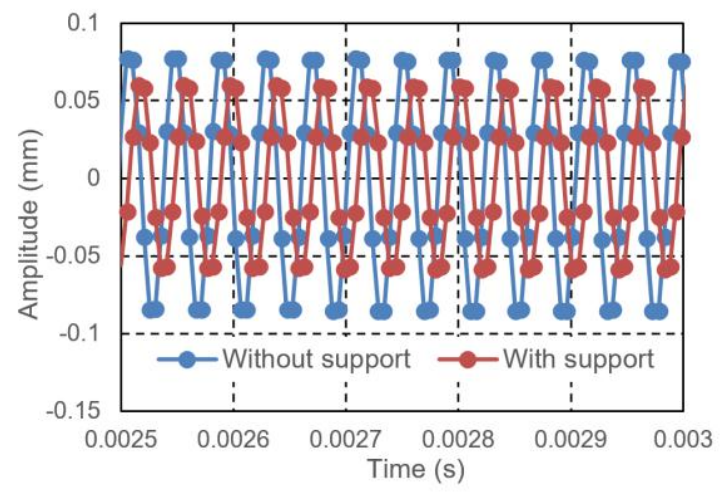

Fig. 10. Amplitude of coil part ( $x$ direction input).

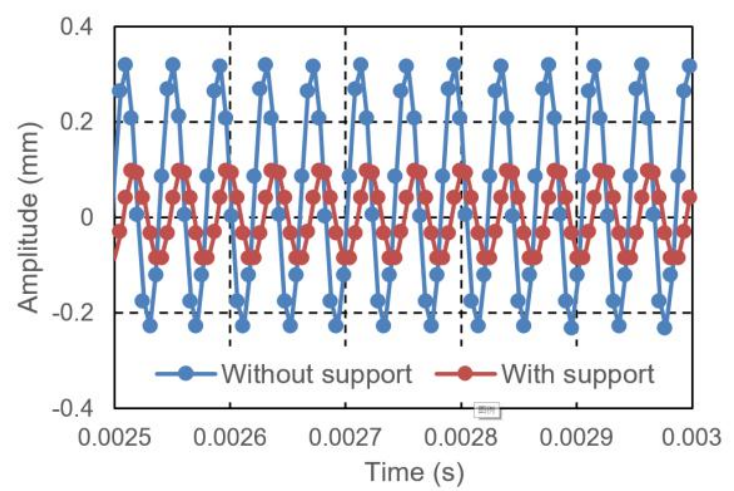

Fig. 11. Amplitude of coil part ( $y$ direction input).

\section{CONCLUSION AND FUTURE POLICY}

Assuming the introduction of a vascular endoscope, the waveguide with the wire stator of $2 \mathrm{~m}$ and the support structure added to the wire stator is designed. The transient response analysis is performed by the finite element method for the model that is the waveguide with the wire stator of $2 \mathrm{~m}$, and it is shown that the wire stator used in the previous study can be reproduced by controlling the input from the viewpoint of the decreasing rate of the amplitude. The transient response is performed by the finite element method for the model of the wire stator with the support structure added, and it was possible to clarify that the damping is affected by the structure and vibration direction. 
As a future policy, the authors will measure the amplitude of the wire stator by experiment and verify the accuracy of the simulation. Regarding the support method of the wire stator, the authors will consider the other support shape and materials other than SUS304 and design the optimum wire stator that does not disturb the progress of ultrasonic vibration by finite element analysis. Ultimately, the authors will design a model of equal size based on these, and aim for stable operation and control of 2-axis drive together with the results of previous study.

\section{REFERENCES}

[1] K. Mizuno, "Angioscopic evaluation of coronary plaque and thrombus," Japanese Journal of Thrombosis and Hemostasis, vol. 8, no. 3, pp. 236-241, 1997.

[2] T. Yano and T. Maeno, "Spherical motor," Journal of The Robotics Society of Japan, vol. 21, no. 7, pp. 740-743, 2003.

[3] N. Takesue et al., "Position control methods of spherical ultrasonic motor," in Proc. IEEE/RSJ International Conference on Intelligent Robots and Systems 2010, pp. 3061-3066, 2010.

[4] T. Sashida and T. Kenjo, An Introduction to Ultrasonic Motors, Oxford: Oxford University Press, 1993.

[5] T. Mashimo, S. Toyama, and H. Ishida, "Design and implementation of a spherical ultrasonic motor," IEEE Transactions on Ultrasonics, Ferroelectrics, and Frequency Control, vol. 56, pp. 2514-2521, 2009.

[6] E. Purwanto and S. Toyama, "Control method of a spherical ultrasonic motor," in Proc. IEEE/ASME international conference on advanced intelligent mechatronics 2003, pp. 1321-1326, 2003.

[7] T. Mashimo, K. Awaga, and S. Toyama, "Development of a spherical ultrasonic motor with an attitude sensing system using optical fibers," in Proc. IEEE International Conference on Robotics and Automation 2007, pp. 4466-4471, 2007.

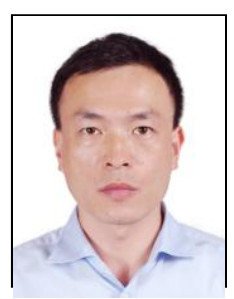

Fulin Wang received M. degree in engineering from Beijing Jiaotong University, Beijing, China, in 2005. Now he studies at Tokyo University of Agriculture and Technology. His current research interests include robotics, AI technology, and welfare technology.

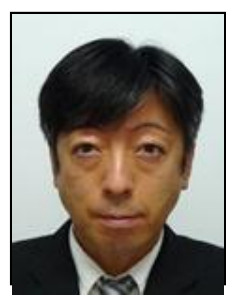

Uichi Nishizawa received $\mathrm{Ph} . \mathrm{D}$. degree in engineering from Tokyo University of Agriculture and Technology, Tokyo, Japan, in 2008. Now he works at Tokyo University of Agriculture and Technology. His current research interests include robotics, aerospace engineering, and welfare technology.

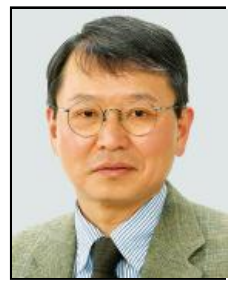

Shigeki Toyama received $\mathrm{Ph} . \mathrm{D}$. degree in engineering from University of Tokyo, Tokyo, Japan, in 1981. Now he works at Tokyo University of Agriculture and Technology. His current research interests include robotics, actuator, and welfare technology. 